УДК 94(571). 057.51

\title{
В.О. Елизарова
}

\section{ВНЕШНИЕ И ВНУТРЕННИЕ ФАКТОРЫ ФОРМИРОВАНИЯ СОВЕТСКОЙ МИГРАЦИОННОЙ ПОЛИТИКИ НА КАМЧАТКЕ В СЕРЕДИНЕ - КОНЦЕ 1920-х гГ.}

\begin{abstract}
Прослежено, каким образом под влиянием внешних и внутренних факторов смещались акценты советской миграционной политики в отношении Камчатки. Вплоть до 1927 г. ее территория не рассматривалась в качестве перспективной базы для переселений. Смена внешне- и внутриполитического курса в конце 1920-х гг. послужила причиной кардинальных изменений государственных планов. Район приобрел значение стратегического, началось комплексное освоение его ресурсов, что, в свою очередь, потребовало усиления демографического и трудоресурсного потенциала. Уже в 1928-1929 гг. появились первые варианты планов переселения на Камчатку, а в 1930 г. начали прибывать первые плановые переселенцы.

Ключевые слова: Камчатка; Дальний Восток; Япония; миграционная политика; переселения.
\end{abstract}

Исторически сложилось, что интенсивность миграционных процессов на территории России в разные временные периоды зависела от государственной инициативы. Без государственного участия вряд ли было возможно осуществить заселение и освоение необжитых, удаленных от центра районов и обеспечить их устойчивое социально-экономическое развитие. К числу таких территорий в 20-е гг. ХХ в. относилась Камчатка. С 1922 г. Камчатская губерния ${ }^{1}$ административно входила в состав Дальневосточной области (далее - ДВО). Навигация была ограничена шестью месяцами в году. Чтобы попасть в Петропавловск - административный центр, нужно было преодолеть путь по железной дороге до г. Владивостока. Затем предстояло плыть на пароходе. Поездка в северные районы Камчатки занимала до одного года, в южные районы - до 2,5 месяцев. Связь по радио, телеграфу и телефону была очень плохой, а в северных районах отсутствовала. На Камчатке не было шоссейных и проселочных дорог, поэтому сообщение между населенными пунктами внутри полуострова было так же затруднительно, как и с внешними.

Интеграция Камчатки в политическое и социальноэкономическое пространство страны в составе Российской империи шла медленными темпами. С приходом советской власти процесс ускорился. Причем усиление государственного интереса к этой территории происходит во второй половине 1920-х гг. Резко изменившаяся внешне- и внутриполитическая концепция советского правительства ускорила реализацию миграционной политики и освоение камчатских ресурсов.

Хотя фактическое осуществление плановых переселений на Камчатку началось с 1930 г., тем не менее, существует необходимость рассмотреть, каким образом происходило вхождение этой территории в орбиту интересов государства. Определение ключевых событий поможет глубже понять его замысел и позволит сформулировать более объективные выводы о целях миграционной политики в отношении Камчатки. Так как в течение рассматриваемого периода Камчатская губерния (впоследствии Камчатский округ) административно входила в состав ДВО (с 1926 г. Дальневосточный край, ДВК), целесообразно проанализировать изменение статуса Дальнего Востока в контексте внешне- и внутриполитической концепции СССР в середине - конце 1920-х гг.
С окончанием Гражданской войны районы Дальнего Востока начали включаться в систему советских преобразований. Значительная территория региона, его оторванность от центра, протяженные сухопутные и морские границы с азиатскими странами, наличие ресурсоемких, исключительно добывающих отраслей обозначили необходимость выстраивания особой государственной стратегии в данном направлении.

Основная внешнеполитическая задача СССР в первой половине 1920-х гг. заключалась в поиске путей выхода из международной изоляции и налаживании отношений с западноевропейскими странами и США. На Дальнем Востоке ЦК РКП(б) с 1921 по 1925 г. решались вопросы о возвращении КВЖД и северной части о. Сахалина, оккупированного Японией [1. С. 20-21]. Временное безвластие в период Гражданской войны привело к усилению экономических позиций иностранных фирм, особенно в островных, полуостровных окраинных зонах Дальнего Востока - на Камчатке и Сахалине.

В 1925 г. народным комиссаром иностранных дел Г.В. Чичериным была сформулирована основная задача советской дипломатии, которая заключалась в установлении дружеских отношений с Англией, США, Францией, Германией и другими западноевропейскими государствами. От успеха в этом направлении зависело, по мнению Г.В. Чичерина, налаживание связей с Китаем и Японией - стратегическими партнерами СССР на Дальнем Востоке. Сложившаяся в первой половине 1920-х гг. международная обстановка оценивалась как период «мирного сожительства» с капиталистическими странами, который необходимо использовать «для ускорения внутреннего строительства СССР» [Там же]. Дальневосточные сырьевые ресурсы рассматривались советским правительством как один из источников этого «ускорения». Но так как последствия Гражданской войны и интервенции существенно подорвали отечественную экономику, государство не имело возможности осуществлять масштабные капиталовложения для создания крупных отраслей промышленности на Дальнем Востоке. Поэтому в 1920-е гг. одним из способов накопления средств в государственном бюджете стало привлечение иностранного капитала в форме концессий.

В это время начала оформляться государственная миграционная политика в общесоюзном формате 2 . 
В октябре 1924 г. Советом Труда и Обороны было принято Постановление «О ближайших задачах колонизации и переселения». В документе впервые были сформулированы и определены главные задачи советской миграционной политики. Ближайшим ее направлением должна была стать разгрузка аграрно-перенаселенных, малоземельных районов страны. Согласно постановлению, в первую очередь должны были заселяться те районы, которые представлялось возможным освоить в кратчайший срок с наименьшей затратой государственных средств. Но ввиду нехватки земель в обжитых районах страны Госпланом СССР в апреле 1925 г. было принято решение о вовлечении в колонизируемый фонд земли и необжитых районов. А в июле 1925 г. декретом ВЦИК и СНК РСФСР объявлялось об открытии планового переселения в районы Поволжья, Сибири и Дальнего Востока. Стихийное перемещение населения из аграрно-перенаселенных западных районов должно было принять, по замыслу государства, организованный характер [2. С. 66-69].

Таким образом, Декретом 1925 г. было положено начало формирования миграционной политики на Дальнем Востоке. Однако территории Крайнего Севера и северо-востока Дальневосточного региона не были включены в список районов, предполагаемых для переселений. Труднодоступные, удаленные и малоосвоенные, к середине 1920-х гг. они представляли собой глухие окраины без какой-либо инфраструктуры. Формирование населения здесь шло в основном за счет естественного прироста. Переселение самотеком в этом направлении практически не осуществлялось.

Уже в 1925 г. региональными органами, Дальневосточным Земельным Управлением (далее - Дальземуправление) и Дальневосточным экономическим совещанием (далее - Дальэкосо) были разработаны два варианта долгосрочного колонизационного плана. Оба плана были рассчитаны на десятилетний срок реализации на Дальнем Востоке. Принципиальное различие лежало в масштабах переселения и в характере самой колонизации [3. 1925. № 12. С. 43, 71]. Дальземуправлением предлагалось за 10 лет вселить на Дальний Восток более миллиона человек, введя в оборот до 60\% необжитых земель. Согласно варианту Дальэкосо в регион должно было прибыть 40 тыс. чел., из которых 30 тыс. - по сельскохозяйственной линии. Второй план был рассчитан на обжитые районы материковой части: Владивостокский, Хабаровский, Амурский, Сретенский и Читинский округа [Там же. 1926. № 4. С. 15]. Примечательно, что обоими вариантами планов территория Камчатки в качестве района для переселений не рассматривалась.

В соответствии с расчетам Дальэкосо быстрое увеличение населения за счет организации переселений должно было произойти лишь в вышеупомянутых округах. Для остальных районов его рост мог быть достигнут только за счет естественного прироста. Так, по оценкам Дальэкосо, население Камчатского округа с 1925 по 1935 г. возросло бы с 30600 до 36600 чел., Сахалинского, в аналогичный период, с 9 тыс. чел. до 11 тыс. чел. [Там же. 1925. № 4. С. 15].

Таким образом, статус Камчатки как необжитого и труднодоступного района обусловил ее исключение из перечня перспективных переселенческих баз. Это отвечало государственной установке - заселять в первую очередь наиболее освоенные земледельческие районы.

В поле зрения региональных органов находились наиболее актуальные для решения в данный момент проблемы. К их числу относились варианты развития экономики Камчатки и господство иностранного капитала в рыбной отрасли.

Особо сильные позиции на Камчатке имели японские предприниматели, которые к началу 1920-х гг. стали «монополистами как по добыче, так и по обработке сырья на морском побережье» [4. С. 86]. Согласно Рыболовной конвенции 1907 г. сдача рыболовных участков в конвенционных водах осуществлялась на равных правах между русскими и японскими рыбопромышленниками. Во время Гражданской войны японцам удалось существенно расширить свою деятельность, в том числе и за счет незаконного захвата новых промысловых участков. В течение 1922-1927 гг. шли советско-японские переговоры, на которых японская сторона добивалась сохранения условий Конвенции 1907 г. [Там же. С. 81-85].

Экономическое влияние Японии и варианты освоения ресурсов полуострова неоднократно обсуждались центральными и региональными органами. Только Комиссией по Камчатским делам ${ }^{3}$ в период с 1923 по 1925 г. было проведено 31 заседание и решено 127 вопросов [5. Оп. 1. Д. 69. Л. 66]. Наиболее целесообразным вариантом, по мнению членов комиссии, могло стать создание государственной организации, которая бы обеспечила комплексное освоение ресурсов Камчатки и снабжение населения. Этому же вопросу в разное время были посвящены доклады и заседания Народного Комиссариата Внешней Торговли, Бюро Съездов Госплана СССР Дальневосточной секции, Дальэкосо. Силами разных ведомств был разработан проект плана о создании государственного акционерного общества, в задачи которого должен был войти охват всех сторон народного хозяйства Камчатки с приблизительным капиталом в 8 млн руб. [5. Оп. 1. Д. 69. Л. 66]. Такая огромная сумма, учитывая труднодоступность полуострова и отсутствие какой-либо инфраструктуры, была целесообразной и могла обеспечить экономическое проникновение государства на эту территорию.

Центр понимал необходимость советского присутствия на Камчатке, но в то же время не располагал достаточными средствами на финансирование такого дорогостоящего проекта. Поэтому для ограничения влияния японского капитала в рыбной отрасли Камчатки в мае 1924 г. было основано Охотско-Камчатское акционерное рыбопромышленное общество (ОКАРО), ставшее первым государственным предприятием на полуострове. В основу работы ОКАРО легли эксплуатация рыбных промыслов, снабжение местного населения, а также скупка золота и пушнины. Организация несла большие издержки, не располагала достаточными средствами, опытным штатом служащих и рабочих, пригодных для промысла. Не хватало тоннажа флота для развертывания масштабного лова и сбыта продукции. Чтобы получить обо- 
ротные средства, ОКАРО приходилось вести на УстьКамчатских речных участках добычу сырья, которое продавалось на месте на японские консервные заводы [6. С. 239].

Несмотря на небольшое количество промысловых участков, эксплуатируемых ОКАРО, для их обслуживания требовались рабочие руки. Немногочисленное местное население не стремилось попасть в число работников ОКАРО. По приблизительным оценкам Дальневосточного Революционного Комитета (далее - Дальревком), на Камчатке рыбаков из числа местных насчитывалось около 14 тыс. чел. [5. Оп. 1. Д. 68. Л. 4 об.]. Для них предпочтительным являлся индивидуальный лов или промысел небольшими кооперациями. Добытая рыба сдавалась частникам или ОКАРО. Именно тогда впервые встал вопрос о необходимости обеспечения камчатской государственной промышленности рабочими руками.

Так как в середине 1920-х гг. Камчатка не располагала благоприятными условиями для переселения на постоянное место жительства людей, а ОКАРО финансовыми возможностями, выходом из сложившейся ситуации стал найм рабочих на сезон. Рабочие вербовались во Владивостоке, затем на пароходе следовали на Камчатку. По окончании путины их вывозили обратно. Помимо русской рабочей силы на камчатских промыслах, как государственных, так и частных, работали японцы. Их высокие производственные навыки, дисциплинированность и непритязательность в быту высоко ценились. К тому же содержание японского рабочего обходилось дешевле на 50 руб. В соотношении русской и японской рабочей силы был существенный разрыв: 1,5 тыс. и 25 тыс. чел. соответственно [Там же]. Следовательно, основной доход от работы на камчатских промыслах получали японцы. По оценкам Госплана СССР, рыбная промышленность Камчатки дала заработок рыбакам в общей сумме 6 млн руб., из них 4 млн руб. получили японские рабочие [5. Оп. 1. Д. 69. Л. 29].

В среде японских рабочих, как на русских, так и на концессионных промыслах, велась активная агитационно-пропагандистская работа. К каждому промысловому участку был приставлен специалист-партиец, ответственный за агитацию. Разрабатывались и специальные инструкции «для вовлечения масс рыбацкого пролетариата во всю политическую борьбу японского рабочего класса» [7. Оп. 1. Д. 25. Л. 15]. Данные эпизоды свидетельствуют о надеждах Советского государства воплотить идею о победе мировой социалистической революции на востоке.

Таким образом, неосвоенность Камчатки сдерживала ее социально-экономическое развитие в 1922 1927 гг. Попытка ограничить экономическое влияние Японии на камчатских рыбных промыслах путем создания ОКАРО не увенчалась успехом, и в 1926 г. организация была расформирована. Тем не менее результаты ее деятельности позволили ближе «увидеть» ситуацию и более отчетливо сформулировать проблемы, требующие государственного вмешательства.

Смена курса в отношении дальневосточных территорий происходит в 1927-1929 гг. На фоне ухудшения отношений СССР со странами Тихоокеанского регио- на, Японией и Китаем, резко изменилась внешнеполитическая концепция, сформулированная Г.В. Чичериным в 1925 г. Был свернут нэп, страна начала готовиться к мобилизации внутренних ресурсов для перехода на рельсы индустриализации.

Новые реалии международной обстановки обусловили необходимость усиления государственных позиций в пограничных районах материковой части Дальневосточного края, а также в тех районах, где влияние противника было наиболее ощутимым - на Камчатке и Сахалине. В таких условиях обозначилась необходимость в разработке продуманных мер, которые могли решить проблему «иностранного враждебного влияния».

Отказ от дальнейшего предоставления концессий японцам мог послужить причиной усугубления внешнеполитической ситуации. Поэтому государством была избрана наиболее оптимальная в сложившихся обстоятельствах стратегия: постепенное ограничение японского влияния на Камчатке через усиление государственного сектора в экономике и обеспечение политического проникновения на территорию путем переселения советских граждан.

Поэтому в июне 1927 г. была создана вторая государственная структура - Акционерное Камчатское общество (далее - АКО, Общество). Учредителями предприятия стали Народный комиссариат внешней и внутренней торговли СССР, Наркомторг РСФСР, BCHX CССР, ВСНХ РСФСР, Далькрайисполком, Госторг РСФСР, Совторгфлот. Совет Общества возглавил нарком Внутренней и Внешней торговли А.И. Микоян [8. С. 61-62].

АКО необходимо было развернуть работу более чем по пятнадцати направлениям, в число которых вошла и организация массовых переселений на Камчатку. Для Общества был составлен «Пятилетний план по колонизации Охотско-Камчатского края», который предполагал развитие рыбной промышленности до экспортного уровня и отказ от использования сезонного труда - «главного зла камчатской рыбной отрасли».

Уже в 1928 г. с Японией была заключена новая Рыболовная конвенция. Было учтено ее положительное экономическое значение, которое заключалось в возможности использования иностранной валюты для развития отечественной рыбной промышленности в регионе [4. С. 89].

Параллельно начинает оформляться миграционный сценарий для тех территорий, которые прежде не значились в списке перспективных переселенческих баз.

В августе 1927 г. Постановлением Политбюро ЦК ВКП(б) Наркомату труда, ВЦСПС, краевым дальневосточным организациям поручалось «разработать ряд мероприятий, способствующих переселению русских рабочих на Дальний Восток вообще, и особенно на Сахалин и Камчатку, создав для этого соответствующие материальные условия, могущие заинтересовать переселенцев» [5. Оп. 1. Д. 114. Л. 250].

Постановлением СТО СССР (12.04.1928 г.) «О переселении в Дальневосточный край» заселение ДВК признавалось «главнейшей задачей» среди переселенческих фондов общесоюзного значения. Данным По- 
становлением Всесоюзному переселенческому комитету необходимо было в 2-недельный срок предоставить перспективный план ассигнований на ближайшее пятилетие и разработать «доклад о формах организации переселений и о тех органах, на которые должно быть возложено проведение переселения этих групп» [5. Оп. 1. Д. 105. Л. 96].

В августе 1928 г. Наркоматом труда была введена в действие инструкция «О порядке переселения в ДВК кустарей, ремесленников, лиц, занимающихся добывающими промыслами и промышленных рабочих» [2. С. 183]. Инструкция определила основную схему переселений на Дальний Восток, в соответствии с которой должна была вестись работа в этом направлении.

В 1929 г. решением Президиума Далькрайисполкома территории Камчатки и Сахалина вошли в список приграничных районов [5. Оп. 1. Д. 126. Л. 105].

В соответствии с изменившейся внешнеполитической обстановкой был подвергнут пересмотру пятилетний план развития Советского Дальнего Востока. Решением Госплана РСФСР Далькрайисполком был обязан «предоставить не позже 01.07.1929 г. доклад о пятилетнем плане развития Советского Дальнего Востока (на 1928/1929 - 1932/1933 гг.) под углом зрения максимального укрепления наших экономических позиций и преграждения японской экспансии с особенно точной проработкой плана сельскохозяйственного переселения и развития всяких промыслов... на Камчатке, в Охотском крае и на Сахалине в целях создания в этих районах усиленного оседания переселенцев из других областей СССР» [5. Оп. 1. Д. 114. Л. 94].

Центральной установкой пересмотренного варианта стало превращение края в «мощный хозяйственный аванпост Советского Союза на берегах Тихого океана». С этой целью намечалось развитие и укрепление экспортных и валютных отраслей хозяйства с «повышенным коэффициентом социалистической реконструкции». Наиболее перспективными из них были обозначены угольная, лесная, рыбная, нефтяная, золотодобыча. Особое значение план придавал политическому укреплению Дальнего Востока, чтобы «всемерно повысить его сопротивляемость агрессивным устремлениям японского империализма» [Там же. Л. 14].

В целях экономического и политического укрепления северных районов Дальневосточного края Планом предполагалось: «Заполнение до 25\% рабочей силы на предприятиях японской рыбопромышленности на Камчатке... Создание хотя бы скромной местной базы для снабжения населения сельскохозяйственной продукцией на Камчатке и Сахалине... Увеличение доли оседлой рабочей силы на Сахалине и Камчатке, чтобы до минимума сократить дорогостоящий завоз сезонной рабочей силы» [Там же].

Отсутствие квалифицированных кадров, знакомых с условиями работы на Камчатке, обусловило в первые годы работы АКО значительный удельный вес японской рабочей силы, доходившей в 1928-1929 гг. до $50 \%$ [9. Оп. 1. Д. 10. Л. 344].

С ростом напряжения в советско-японских отношениях задача вытеснения японского труда начала приобретать политическую окраску и в дальнейшем ускорила появление планов переселения на Камчатку.
Уже в конце 1920-х гг. стал активно обсуждаться вопрос о вытеснении японской рабочей силы с камчатских рыбных промыслов и замены ее советской. Региональными органами разрабатывались проекты сокращения ввоза японских рабочих [5. Оп. 1. Д. 126. Л. 23, 26].

Форсированию данных мероприятий способствовали и тревожные донесения от Камчатского Окружного бюро ВКП(б). Например, в закрытом письме Крайкому от 20.12.1929 г. упоминались случаи участившихся забастовок японских рабочих на заводах АКО. Так, «в разгар путины 1929 г. на $\mathrm{PK}^{4}$ № 3 в Озерной 27 рабочих-японцев отказались от работы и предъявили ряд требований, которые не входили в коллективный договор». На заводе № 4 бастовали 32 японца, «а четыре человека украли катер и скрылись». При фрахтовке АКО тресколовных шхун у японцев отмечался их агрессивный настрой, «над нашими работниками издевались, допускали угрозы...» [7. Оп. 1. Д. 106. Л. 172 об.].

Факты дезорганизаторской и антисоветской деятельности японцев в территориальных водах Камчатки и Сахалина спустя месяц стали предметом секретного доклада Комиссии ЦИК СССР по обследованию Камчатского и Сахалинского округов Дальневосточного края (от 23.01.1930 г.). В сообщении была подчеркнута исключительная роль Японии в жизни северных округов ДВК. Автор доклада, председатель Камчатско-Сахалинской комиссии ЦИК СССР А.В. Шотман обращал внимание на «активность японцев в своих антисоветских политических мероприятиях», заключавшихся в противопоставлении материальных и культурных условий при концессиях - складывающейся советской модели на Камчатке и Сахалине [5. Оп. 1. Д. 139. Л. 102-118].

А.В. Шотманом был сделан акцент на то, что «наиболее серьезными мерами противодействия японской агрессии до сих пор является организация $\mathrm{AKO} \mathrm{и} \mathrm{ACO}^{5}$, предусматривающих целый комплекс мероприятий по закреплению советского влияния на берегах Тихого океана» [Там же. Л. 119-120].

В заключении доклада Комиссией ЦИК было отмечено, что «крупные заводы на Сахалине и Камчатке с постоянным кадром рабочих являются не меньшим оплотом восточного рубежа СССР, чем части ОДВА ${ }^{6}$ » [Там же. Л. 122-123].

Приведенные выдержки свидетельствуют о том, что рост напряжения в советско-японских отношениях способствовал окончательному определению стратегических планов СССР на Дальнем Востоке и его северо-восточных границах. Разворачивание деятельности АКО на Камчатке решало проблему окончательного закрепления территории за Советским государством, обеспечивало его экономическое проникновение, одновременно способствуя ограничению японского капитала. Достичь поставленной цели было невозможно без усиления демографического потенциала. Уже в 1930 г. в структуре АКО были созданы два новых управления: Колонизационное и Переселенческое, которые должны были способствовать созданию на Камчатке «кадра местной наемной рабочей силы». Главная контора Общества была переведена в 
г. Петропавловск. А весной 1930 г. Камчатка принимала первых плановых переселенцев.

Таким образом, под влиянием комплекса внешне- и внутриполитических факторов была решена судьба самых малонаселенных и неосвоенных территорий Дальнего Востока. Смещение акцентов в государственной миграционной концепции во второй половине 1920-х гг. ускорило интеграцию Камчатки в русло государственных преобразований. Район приобрел значение стратегического, началось освоение его ресурсов. В относительно сжатые сроки (1927-1930 гг.) получила оформление и развитие миграционная политика, которая должна была решить задачи политического и экономического закрепления территории за СССР.

\title{
ПРИМЕЧАНИЯ
}

\begin{abstract}
${ }^{1}$ После восстановления советской власти на Дальнем Востоке Президиум ВЦИК 15 ноября 1922 г. принял Постановление «Об объединении РСФСР и ДВР в качестве Дальневосточной области», в состав которой вошли губернии Прибайкальская, Приамурская, Амурская, Приморская, Камчатская. 6 декабря 1922 г. Камчатская область была переименована в Камчатскую губернию.

4 января 1926 г. постановлением ВЦИК СССР губернско-уездное административное деление заменено окружным и районным, образован Дальневосточный край (ДВК) с административным центром в г. Хабаровске, в состав края вошел Камчатский округ.

2 Передвижение населения и внутренние миграции были закреплены в Земельном кодексе РСФСР 1922 г. В этом же году был основан Государственный научно-исследовательский колонизационный институт, позднее переименованный в Институт землеустройства и переселения.

${ }^{3}$ Комиссия по Камчатским делам была создана в 1923 г. при Дальневосточном революционном комитете. В 1924 г. была реорганизована в секцию по Камчатским делам при Дальневосточном плановом комитете.

${ }^{4}$ РКЗ - рыбоконсервный завод.

${ }^{5}$ АСО - Акционерное Сахалинское Общество, созданное по государственной инициативе в 1929 г. для эксплуатации ресурсов северного Сахалина.

${ }^{6}$ ОДВА - Особая Дальневосточная армия. Создана в августе 1929 г. приказом Реввоенсовета СССР для обеспечения обороны границ Приморского, Хабаровского краев и Забайкалья. В январе 1930 г. переименована в Особую Краснознаменную Дальневосточную армию (ОКДВА).
\end{abstract}

\section{ЛИТЕРАТУРА}

1. Пикалов Ю.В. Переселенческая политика и изменение социально-классового состава населения Дальнего Востока РСФСР (ноябрь 1922 июнь 1941 г.). Хабаровск : Изд-во ХГПУ, 2003. 214 с.

2. Платунов Н.И. Переселенческая политика Советского государства и ее осуществление в СССР (1917 - июнь 1941 гг.). Томск : Изд-во Том. ун-та, 1976. $283 \mathrm{c.}$

3. Экономическая жизнь Дальнего Востока. Хабаровск : Изд-е Дальневост. краев. исполнит. комитета.

4. Кошкарева С.Г. Советская концессионная политика на Северо-Востоке страны в 1920-1945 гг. Петропавловск-Камчатский : Изд-во КамГУ им. Витуса Беринга, 2012. 155 с.

5. Государственный Архив Хабаровского края (далее - ГАХК). Ф. Р-1228. Представительство Дальневосточного Краевого Исполнительного Комитета в Москве.

6. Отчет Дальревкома и Дальэкосо за 1923-1924 год / под ред. М.П. Копытина, П.Е. Терлецкого. Владивосток, 1925.572 с.

7. ГАХК. Ф. П-2. Дальневосточный краевой комитет ВКП(б).

8. Ильина В.А. Акционерное Камчатское общество в хозяйственном освоении и развитии Камчатки в 1927-1941 гг. ПетропавловскКамчатский : Изд-во КамГУ им. Витуса Беринга, 2013. 279 с.

9. Государственный Архив Камчатского края. Ф. Р-541. Камчатская комплексная экспедиция Наркомата Пищевой Промышленности СССР по исследованию Камчатки.

Статья представлена научной редакцией «История» 18 ноября 2016 г.

\section{EXTERNAL AND INTERNAL FACTORS OF THE SOVIET MIGRATION POLICY FORMATION IN KAMCHATKA IN THE MIDDLE AND LATE 1920S}

Vestnik Tomskogo gosudarstvennogo universiteta - Tomsk State University Journal, 2017, 414, 67-72.

DOI: 10.17223/15617793/414/10

Victoria O. Elizarova, Kamchatka State University named after Vitus Bering (Petropavlovsk-Kamchatsky, Russian Federation). E-mail: vestnikhel@gmail.com

Keywords: Kamchatka; Far East; Japan; migration policy; migrations.

The article describes the way the Soviet migration policy trends connected with Kamchatka were changing under external and internal factors influence. The research is based on the materials of Khabarovsk and Petropavlovsk-Kamchatsky State Archives and scientific literature. Till 1927, the Soviet state did not suppose Kamchatka to be a prospective territory for transmigration. This territory was not included into the first Soviet Far East migration and colonization plans that appeared in 1925. But such plans for Kamchatka appeared in 1928-1929. The first planned settlers arrived here in 1930. Kamchatka became one of the strategic points and its forced resources development started. The identification of the most important events allowed making objective conclusions about the state migration policy goals and reasons of its forced implementation in Kamchatka in the late 1920s - early 1930s. The external factor was connected with the increase of political strain between the USSR, Japan and China, and a significant Japanese economic influence in Kamchatka. The situation required the strengthening of the state positions in the region. The internal factor was connected with the end of the new economic policy in the late 1920s, the beginning of industrialization, the implementation of the idea of socialism construction in a separate country. These trends of internal policy led to the necessity of the country's internal resources mobilization. That is why the Soviet state chose the reasonable line of a gradual reduction of Japanese economic influence in Kamchatka due to the reinforcement of the state sector in the region's economy and political integration of the peninsula by means of the migration policy. In 1927, a special state agency, the Kamchatka Joint-Stock Company (the Soviet abbreviation AKO), was established. It became the conductor of the state policy, including migration. In Kamchatka the forced development of fishing industry of export level started, and it demanded labor. In 1930, special AKO structures, responsible for the state migration policy implementation, were established. The first planned migrants in Kamchatka appeared in the spring of 1930. The author concluded that in the late 
1920s the state's assessment of Kamchatka changed greatly. Under the influence of external and internal factors Kamchatka's geopolitical status increased, active development of its resources started, a large state economic enterprise was founded to represent Soviet interests in the region. Within a short period of time (1927-1930) the state migration policy started because without its implementation the economic and political integration of the territory into the USSR was impossible.

\section{REFERENCES}

1. Pikalov, Yu.V. (2003) Pereselencheskaya politika i izmenenie sotsial'no-klassovogo sostava naseleniya Dal'nego Vostoka RSFSR (noyabr' 1922 iyun' 1941 g.) [Resettlement policy and changes in the social and class composition of the Far Eastern population of the RSFSR (November 1922 - June 1941)]. Khabarovsk: Khabarovsk State Pedagogical University.

2. Platunov, N.I. (1976) Pereselencheskaya politika Sovetskogo gosudarstva i ee osushchestvlenie v SSSR (1917 - iyun' 1941 gg.) [Resettlement policy of the Soviet state and its implementation in the USSR (1917 - June 1941)]. Tomsk: Tomsk State University.

3. Ekonomicheskaya zhizn' Dal'nego Vostoka. (n.d.).

4. Koshkareva, S.G. (2012) Sovetskaya kontsessionnaya politika na Severo-Vostoke strany v 1920-1945 gg. [Soviet concession policy in the NorthEast of the country in 1920-1945]. Petropavlovsk-Kamchatsky: Kamchatka State University.

5. State Archive of Khabarovsk Krai (GAKhK). Fund R-1228. Predstavitel'stvo Dal'nevostochnogo Kraevogo Ispolnitel'nogo Komiteta v Moskve [Representation of the Far East Provincial Executive Committee in Moscow].

6. Kopytin, M.P. \& Terletskiy, P.E. (eds) (1925) Otchet Dal'revkoma i Dal'ekoso za 1923-1924 god [Report of the Far Eastern Revolution Committee and Dalekoso for 1923-1924]. Vladivostok: Knizhnoe delo.

7. State Archive of Khabarovsk Krai (GAKhK). Fund P-2. Dal'nevostochnyy kraevoy komitet VKP(b) [Far Eastern Regional Committee of the CPSU (b)].

8. Il'ina, V.A. (2013) Aktsionernoe Kamchatskoe obshchestvo v khozyaystvennom osvoenii i razvitii Kamchatki v 1927-1941 gg. [Kamchatka JointStock Company in the economic development of Kamchatka in 1927-1941]. Petropavlovsk-Kamchatsky: Kamchatka State University.

9. State Archive of Kamchatka Krai. Fund R-541. Kamchatskaya kompleksnaya ekspeditsiya Narkomata Pishchevoy Promyshlennosti SSSR po issledovaniyu Kamchatki [Kamchatka complex expedition of the People's Commissariat of the USSR Food Industry to explore Kamchatka].

Received: 18 November 2016 